\title{
Catalogue Off Rodman
}

Visual Arts Students - Sueda Akkor, Fraser Brown, Nicola Ciaramella, Alysha Eagleton, Miranda Farrell, Jennifer Judson, Kevin Minow, Sara Mitchell, Sydney Nikulka, Jasmine Said, Maya Slominski, Marissa Tomlinson, Kaia Toop, Jessica Wright

French Studies Students - Leanna Ardron, Evan Arseneau, Taylor Ayres, Annette Beauchamp, Alyssa Berardocco, Meaghan Bisson, Stephanie Brule, Laura Burey, Tyler Cazes, Christina Ciantar, Sabrina Colella, Daniel Cursio, Julia Dimatteo, Kendall Farmer, Shawn Girard, Cassandra Gordon, Jaimee Gregoire, Kathryn Joron, Kelsey Kavanagh, Chelsea Kellner, Karly Knight, Madison Lucio, Maryann Mazuran, Adrianna Medyk, Alexis Merpaw, Sarah Mesquita, Alexandra Papadakis, Caterina Stambolic, Hannah Sukkau, Alyssa Tiangco, Melissa Timgren, Heather Turner, Alanna Vreman, Carole Webster, Rhiannon White

(Photo credit Catherine Parayre)

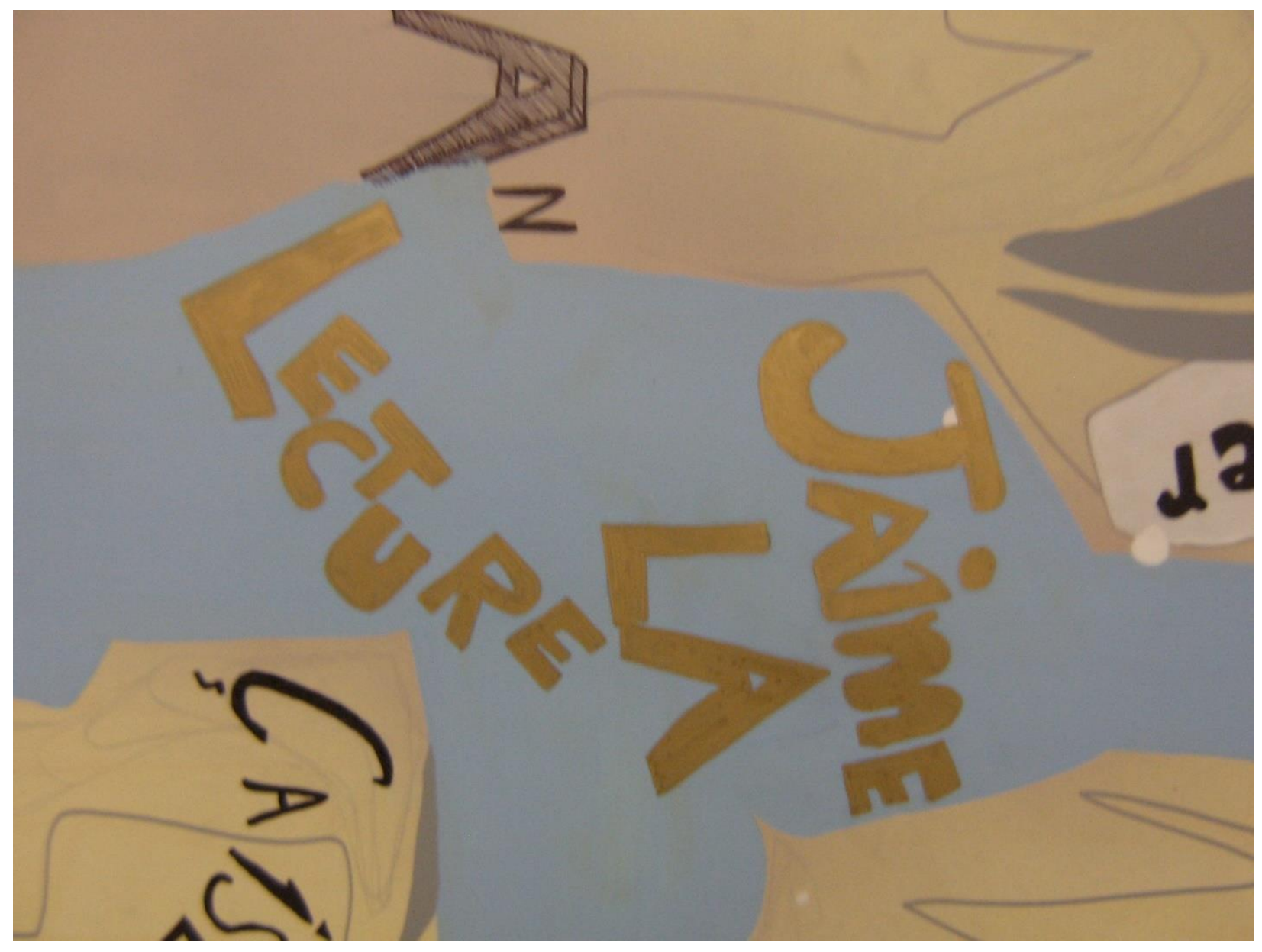


Text on canvas / Texte sur toile
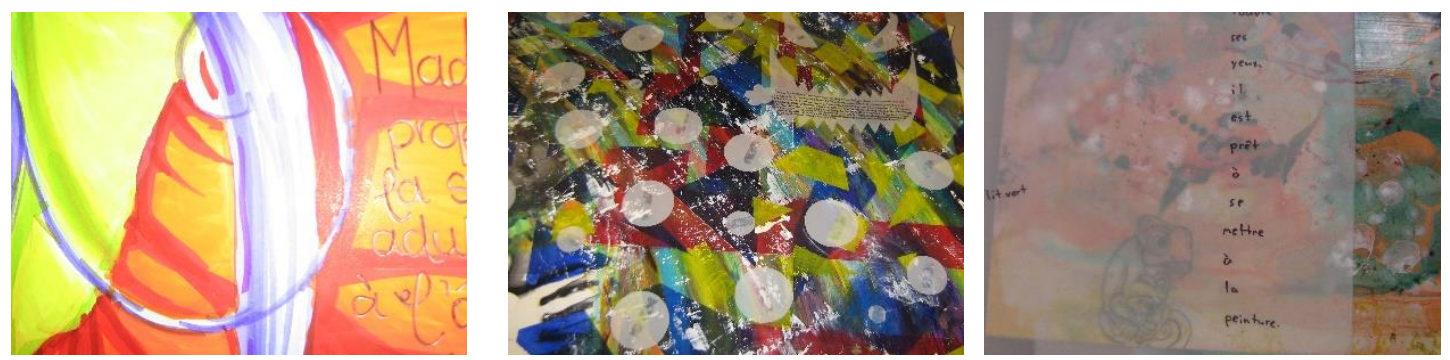

Text on a side / Texte sur le côté
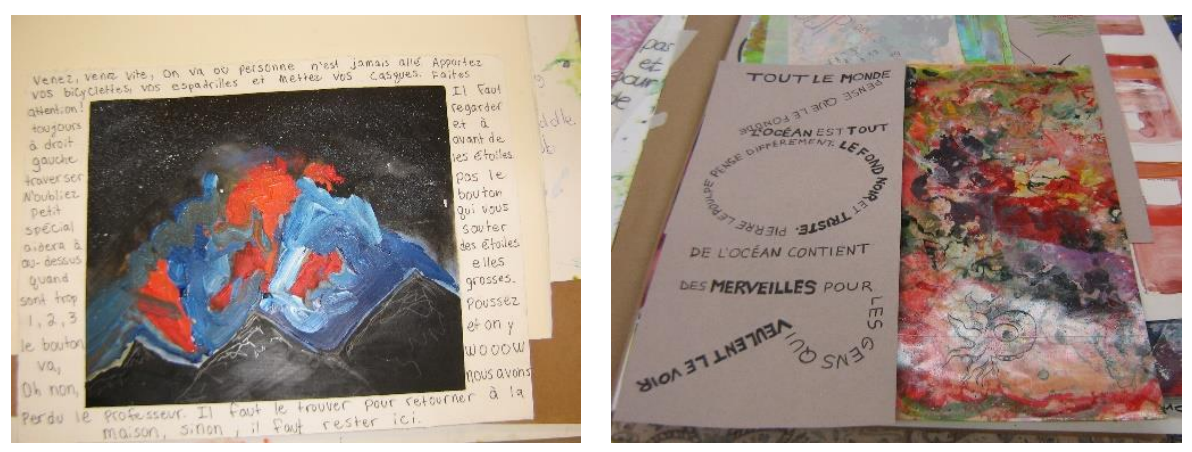

\section{Vegetation / Végétation}

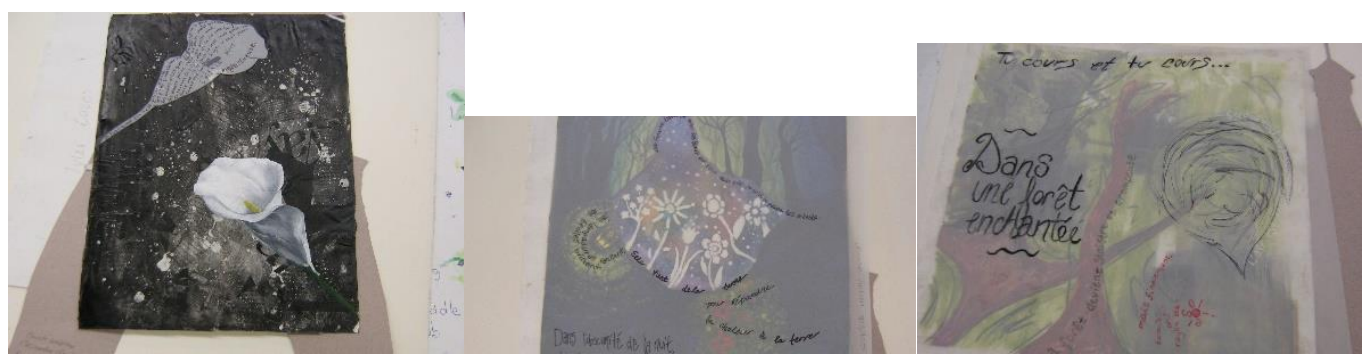


Animals / Animaux

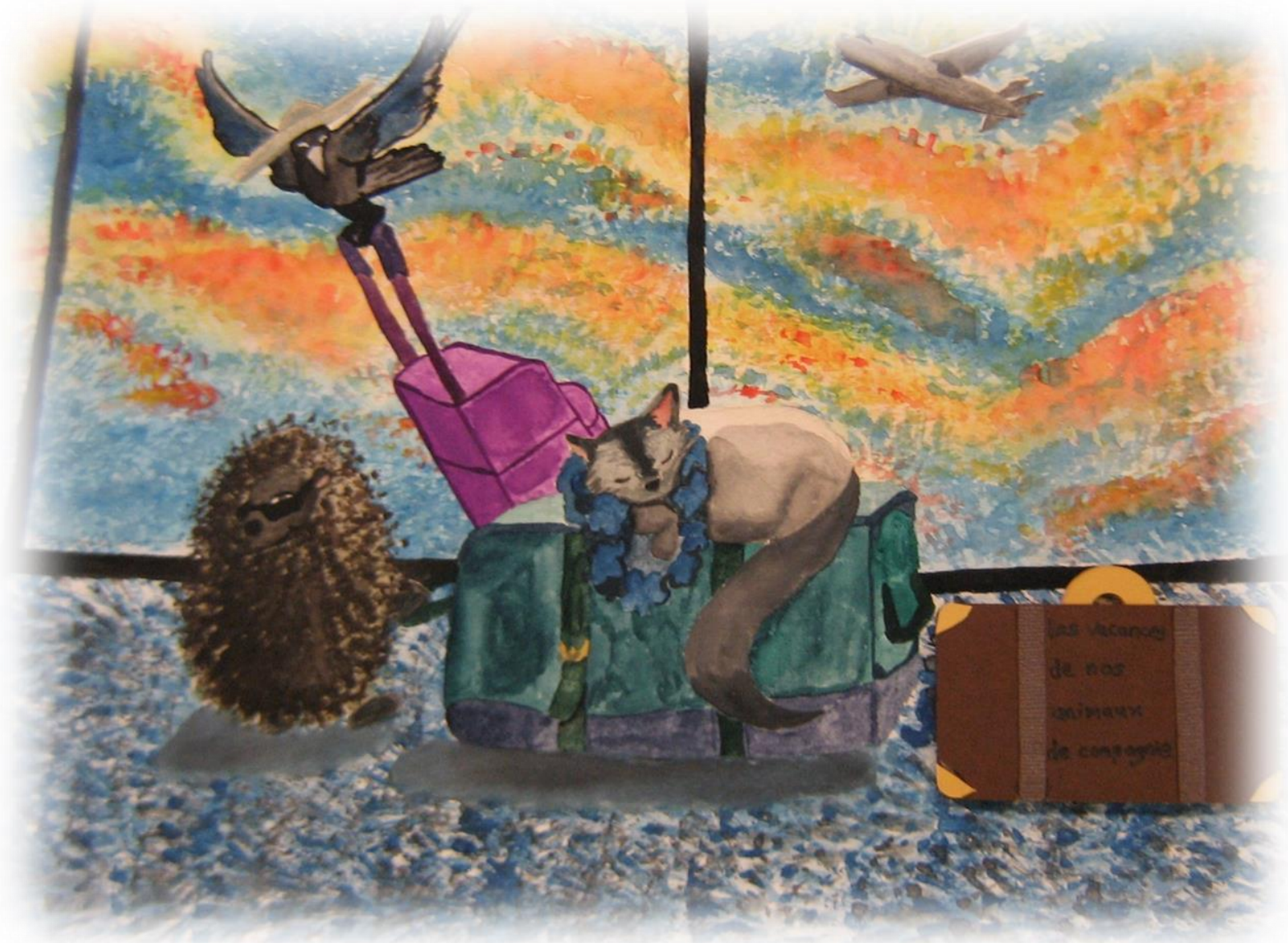



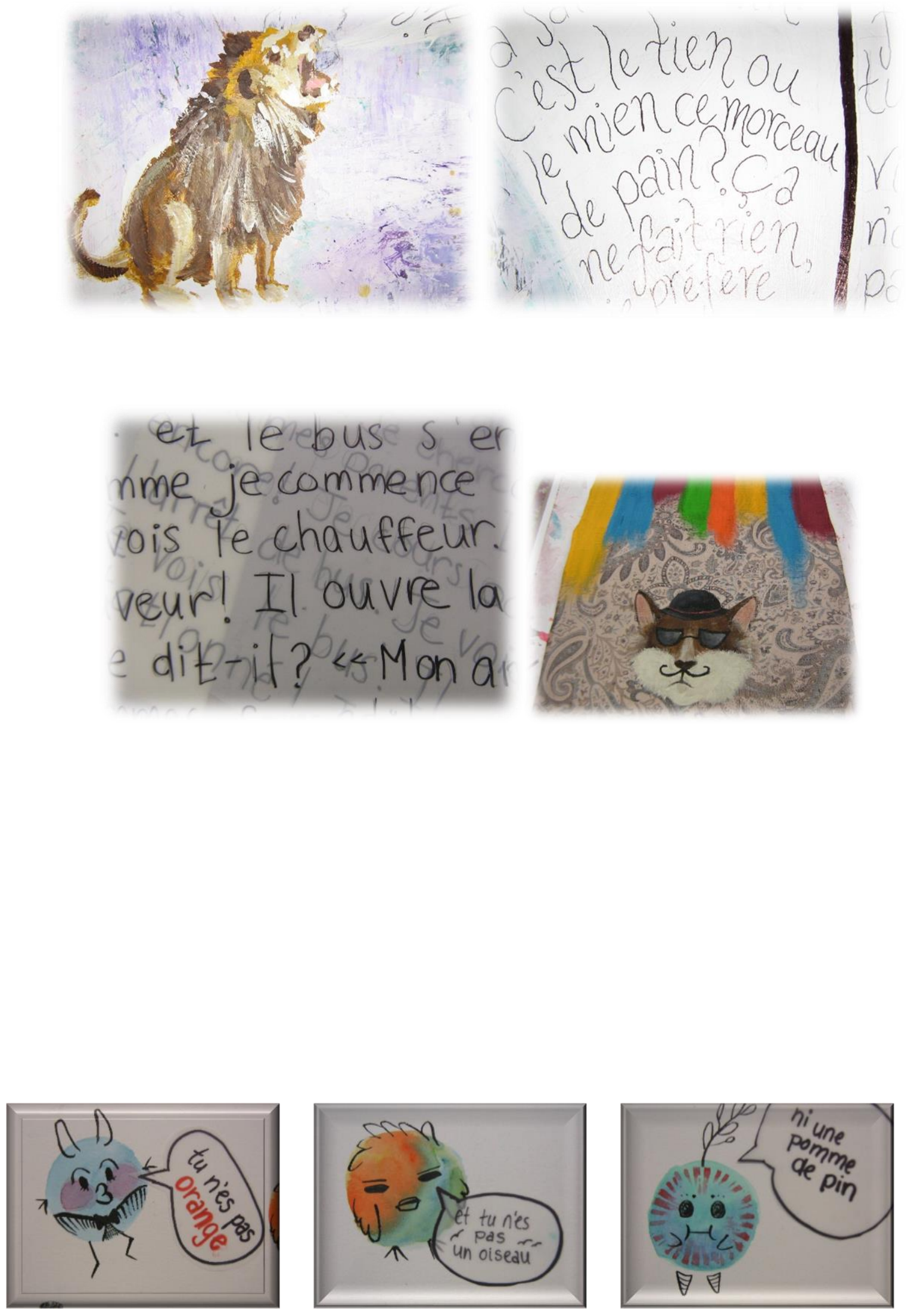